\title{
Effectiveness of Different Treatment Regimens on Eradication of Helicobacter Pylori Infection (A Single Center Experience in Kuwait)
}

\author{
HASSAN B. ABD EL-NABY, M.D.*; AHMED M. ABD EL-ALEEM, M.D.**; \\ WAFAA A. AL-HASHASH, M.D.*** and SHERIF S. MEHREM, M.D.*** \\ The Department of Endemic \& Infectious Diseases, Faculty of Medicine, Suez Canal University*, Ismailia, Egypt \\ The Department of Internal Medicine, Faculty of Medicine, Ain Shams University**, Cairo, Egypt and \\ The Department of Gastroenterology, Al-Sabah Hospital, Kuwait***
}

\begin{abstract}
Background: Helicobacter pylori treatment still remains a challenge for physicians, and no current first-line therapies are able to cure the infection in all treated patients, recent studies reported declining in eradication rate with commonly usedclarithromycin based triple therapy and high cure rate was observed in patients treated by other regimens such as bismuth based therapy.
\end{abstract}

Aim of the Study : To evaluate the effectiveness of the different regimens (Clarithromycin based triple therapy, bismuth based therapy and levofloxacin based therapy) on eradication of H.pylori infection.

Methods: The data of $510 \mathrm{H}$. pylori-infected treatmentnaïve subjects (215 males, 295 female) were collected retrospectively through period between January 2014 and December 2016. Patients treated at Gastroenterology Clinic Al-Sabah Hospital Kuwait. Four hundred and twenty nine patients treated by clarithromycin based triple therapy, 75 patients treated by bismuth containing quadruple therapy. C13 urea breath test was used for confirm eradication.

Results: Eradication rate was significantly higher in 10 days bismuth based quadruple regimen than 14 days clarithromycin based triple regimen (96\%, 77\% respectively) $(p<0.001)$ Levofloxacin based triplę therapy and bismuth based quadruple therapy were effective ${ }^{2 \text { nd }}$ line therapy $(\geq 90 \%$ cure rate).

Conclusion: Bismuth based quadruple regimen more effective therapy for H.pylori infection than clarithromycin based triple regimen. Levofloxacin based triple and bismuth based quadruple regimens are effective ${ }^{2 n d}$ line therapy with high cure rate.

Key Words: Helicobacter Pylori Infection.

\section{Introduction}

HELICOBACTER pylori is chronic infection of stomach causing chronic gastritis, gastroduodenal

Correspondence to: Dr. Hassan B. Abd El-Naby, The Department of Endemic \& Infectious Diseases, Faculty of Medicine, Suez Canal University, Ismailia, Egypt ulcers, and gastric cancer, approximately more than $50 \%$ of population infected worldwide most of them in developing countries [1,2]. Eradication of $\mathrm{H}$. pylori has been recommended for all infected subjects as it is important in treating gastrointestinal diseases and preventing its complications, multiple regimens consist of proton pump inhibitor plus antibiotics combinations have been used for treatment of infected individuals [3]. Clarithromycin based triple therapy thought to be one of the most effective regimen for H.pylorieradication. However, with increasing clarithromycin resistance the eradication rate achieved by this regimen has been declining with less than $80 \%$ cure rate that consider it as sub-optimal therapy for H.pylori [4-6]. Bismuth quadruple therapy is currently recommended as an alternative first-line treatment for $\mathrm{H}$. pylori infection as it provides superior eradication with similar safety and tolerability to standard therapy $[7,8]$. For patients in areas where clarithromycin resistance is high ( $>15$ percent) bismuth-containing or concomitant non-bismuth containing quadruple therapy should be used as first-line therapy [9]. The main problem of the quadruple regimen is the administration of four drugs in a complex scheme and possibly decreased compliance. Furthermore, bismuth salts are not available in all countries. However, side effects associated with the medication do not occur commonly and it can be stated that bismuth for the treatment of $\mathrm{H}$. pylori is safe and well tolerated [10]. In Kuwait, bismuth containing quadruple therapy (Pylera) and other different regimens are available for treatment of $\mathrm{H}$. pylori so we aimed to evaluate the efficacy of these different regimens in achievement of high eradication rate among Kuwaiti patients in order to establish a more effective first-line regimen for $\mathrm{H}$. pylori in Kuwait. 


\section{Subjects and Methods}

Retrospective study was conducted between January 2015 and December 2016 at Gastroenterology Clinic Al-Sabah Hospital Kuwait. Patient's data collected from medical files of $510 \mathrm{H}$. pyloriinfected Adult Kuwaiti (aged $\geq 18$ years) were included in the study. All patients were diagnosed as $\mathrm{H}$. pylori positive by:

1- Rapid urease test (CLO test).

2- 13 C-urea breathe test.

All patients were received 1st line therapy:

The 14-day clarithromycin based triple therapy (Esmoprazole 40mg BD plus amoxicillin 1gm BD and clarithromycin 500mg BD).

The 10-day course of bismuth containing quadruple therapy (Esmoprazole 40mg BD plus Bismuth subsalicylate $420 \mathrm{mg}$, Metronidazole $375 \mathrm{mg}$ and tetracycline $375 \mathrm{mg}$ PO q6hr).

The 10-day course of Levofloxacin based triple therapy (Esmoprazole 40mg BD plus levofloxacin 500mg OD and amoxicillin BD).

\section{The 10-day sequential therapy:}

5 days of Esmoprazole 40mg BD and amoxicillin $1 \mathrm{gm}$ BD followed by 5 days of Esmoprazole $40 \mathrm{mg}$ BD plus clarithromycin 500mg BD and metronidazole 400mg BD).

All patients who included in the study completed treatment duration without drop out. Four to six weeks after completing the therapy, successful $\mathrm{H}$. pylori eradication was defined by a negative 13C urea breath test. Patients who failed to cure 1 st line therapy were treated by 2 nd line therapy (bismuth containing quadruple therapy and levofloxacin based triple therapy (Esmoprazole 40mg BD plus levofloxacin 500mg once daily and $1 \mathrm{~g}$ of amoxicillin twice daily).

\section{Results}

\section{Demographic data of subjects:}

A total of $510 \mathrm{H}$. pylori-infected treatmentnaïve subjects were included in the study ( 215 males, 295 female) their mean age was $45.8 \pm 16.34$, their BMI was $30.02 \pm 10$ and 70 patients were smokers. Four hundred and twenty nine patients treated by clarithromycin based triple therapy, 75 patients treated by bismuth containing quadruple therapy, 4 patients treated by sequential therapy and 2 patients treated by levofloxacin based triple therapy (Table 1).
Table (1): Baseline characteristics, demographic criteria of studied subjects $(\mathrm{n}=510)$.

\begin{tabular}{ll}
\hline Baseline characters & \\
\hline Age (mean \pm SD), year & $45.8 \pm 16.34$ \\
Gender (female/male) & $(295 / 215)$ \\
BMI $\left(\mathrm{kg} / \mathrm{m}^{2}\right)$ & $30.02 \pm 10.09$ \\
Smoking $n(\%):$ & \\
$\quad$ Non-smoker & 408 \\
Current smoker & 70 \\
X-smoker & 32 \\
1st line therapy $n(\%):$ & \\
Clarithromycin triple therapy & 429 \\
Bismuth containing quadruple therapy & 75 \\
Levofloxacin triple therapy & 2 \\
Sequential therapy & 4 \\
\hline
\end{tabular}

First-line therapy:

Overall eradication rate was $80 \%$ among all treated patients who completed the entire course of therapy and returned for follow-up Fig. (1).

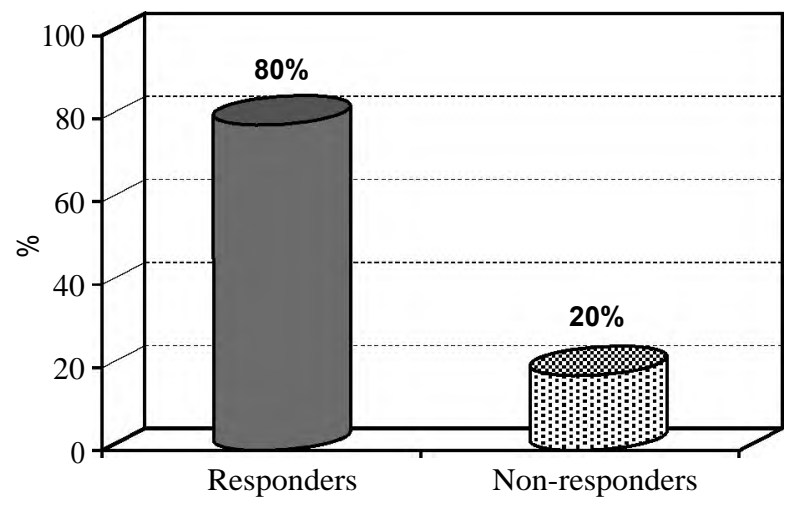

Fig. (1): Eradication rate of H. Pylori in treated patients with 1 line therapy.

\section{Clarithromycin based therapy:}

Four hundred and twenty nine patients treated by standard clarithromycin based triple therapy of them 331 patients were responders with $77 \%$ eradication rate with non-significant high cure rate among females, statistical significant low eradication rate in smokers $(p<0.001)$, otherwise no significant difference founded regarding age and BMI between responders and non-responders to treatment (Table 2).

\section{Bismuth based quadruple therapy:}

Seventy two patients from a total of 75 patients treated by Bismuth containing quadruple therapy were responders with $96 \%$ eradication rate (Table $3)$. 
Table (2): Patients treated by 1 st line clarithromycin based triple therapy $(n=429)$.

\begin{tabular}{|c|c|c|c|}
\hline Baseline data & Responders & $\begin{array}{c}\text { Non- } \\
\text { responders }\end{array}$ & $\begin{array}{c}p- \\
\text { value }\end{array}$ \\
\hline Age (mean $\pm \mathrm{SD})$, year & $48.32 \pm 16.71$ & $41.63 \pm 11.78$ & 0.27 \\
\hline \multicolumn{4}{|l|}{ Gender n (\%): } \\
\hline Male & 139 & 39 & \multirow[t]{2}{*}{0.698} \\
\hline Female & 192 & 59 & \\
\hline BMI, $\mathrm{kg} / \mathrm{m}^{2}$ & $30.28 \pm 11.85$ & $29.61 \pm 5.9$ & 0.33 \\
\hline \multicolumn{4}{|l|}{ Smoking $n(\%)$ : } \\
\hline Non-smoker & $282(65.7 \%)$ & $65(15 \%)$ & \multirow[t]{3}{*}{$>0.001$} \\
\hline Current smoker & $34(8 \%)$ & $24(5.6 \%)$ & \\
\hline $\mathrm{X}$-smoker & $15 \quad(3.5 \%)$ & $9(2 \%)$ & \\
\hline
\end{tabular}

Table (3): Patients treated by 1 st line Bismuth containing quadruple therapy $(n=75)$.

\begin{tabular}{llll}
\hline Baseline data & Responders & $\begin{array}{c}\text { Non- } \\
\text { responders }\end{array}$ & $\begin{array}{c}p \text { - } \\
\text { value }\end{array}$ \\
\hline Age (mean \pm SD), year & $40.2 \pm 12.01$ & $47.67 \pm 23.8$ & 0.041 \\
$\begin{array}{l}\text { Gender } n(\%): \\
\quad \text { Male }\end{array}$ & 32 & 1 & 0.704 \\
$\quad$ Female & 40 & 2 & \\
BMI, kg/m ${ }^{2}$ & $29.52 \pm 5$ & $28.35 \pm 2.76$ & 0.41 \\
Smoking $n(\%):$ & & & \\
$\quad$ Non-smoker & $56(74.7 \%)$ & $2(2.7 \%)$ & 0.382 \\
$\quad \begin{array}{ll}\text { Current smoker } \\
\text { X-smoker }\end{array}$ & $9(12 \%)$ & 0 & \\
\hline
\end{tabular}

Efficacy of clarithromycin based therapy versus bismuth based quadruple therapy as 1st line therapy:

Eradication rate was significantly higher in 10 days bismuth based quadruple regimen than 14 days clarithromycin basedregimen ( $96 \%$ vs. $77 \%$ ) $(p<0.001)$ Fig. (2).

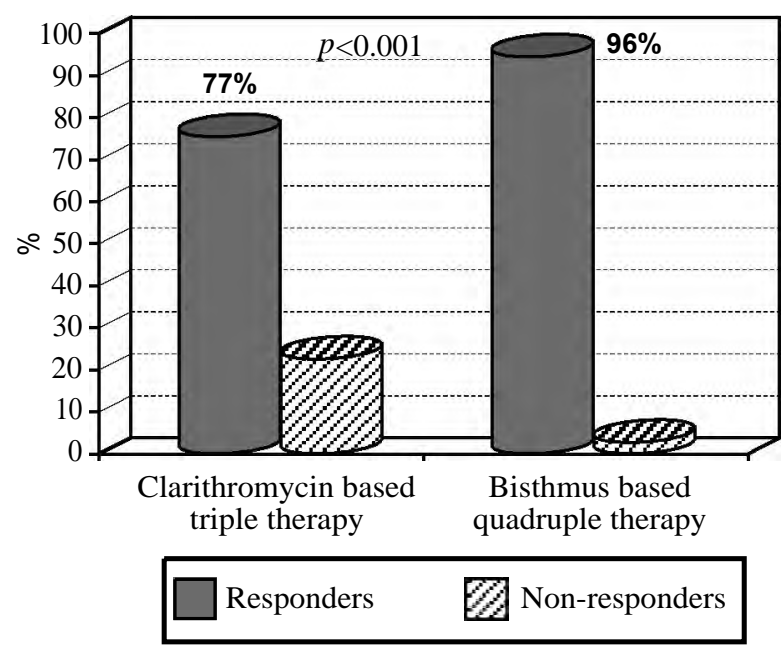

Fig. (2): Efficacy of clarithromycin based therapy versus bismuth based quadruple therapy as 1 st line therapy.

\section{2nd line therapy (Table 4):}

\section{Bismuth containing quadruple therapy:}

Seventy eight patients whose failed cure with $1^{\text {st }}$ line therapy for $\mathrm{H}$. pylori eradication were treated by bismuth containing quadruple therapy showed high eradication rate with 76 cured patients, only 2 patients were non-responders and need 3 rd line therapy also there was no significant differences between responders and non-responders regarding age, gender, BMI and smoking.

\section{Levofloxacin based triple therapy:}

Fifty eight patients whose failed cure with 1 st line therapy for $\mathrm{H}$. pylori eradication were treated by Levofloxacin based triple therapy (Levofloxacin 500mg OD, Amoxicilline 1g BID, Esomperazole 40mg BID) as second line therapy showed high eradication rate with 57 cured patients, only 1 patients were non-responders and need 3 rd line.

\section{Discussion}

Eradication of $\mathrm{H}$. pylori infection needs combinations of 2-3 antibiotics along with a Proton Pump Inhibitor (PPI), there are different treatment regimens have been used for eradication of $\mathrm{H}$. pylori infection. However, no treatment regimen can guarantees cure of $\mathrm{H}$. pylori infection in $100 \%$ of patients [11,12]. Selection ofoptimal therapeutic regimens for treatment of patients should consistently achieve high eradication rates exceeding $90 \%$ $[13,14]$. The present study showed that the H. pylori eradication rate in standard clarithromycin based therapy was $77 \%$ which is lower than accepted eradication rate of optimal therapy for $\mathrm{H}$. pylori $[13,14]$ in agreement with findings of several recent large clinical trials and meta-analyses [14-16] and repeated samefinding of two recent clinical trials in Kuwait [17,18] (Alazmi et al., 2010) (Alboraie et al., 2015). These results indicate that the therapeutic effect of clarithromycin for H. pylori eradication is declining; that may be related to clarithromycin resistance of infecting $\mathrm{H}$. pylori strains. Also we noticed that non-responders to clarithromycin had non-significant high BMI $(29.61 \pm 5.9)$ consistent with previous study [19] that increasing suspicion of BMI role in treatment success, obese patient have high distribution volume of the drug with low concentration at gastric mucosa. Most of responders to standard triple therapy $(65.7 \%)$ were non-smokers with statistically significant in comparison with non-responders $(p<0.001)$ in agreement with study reported that Smoking is a risk factor for treatment failure may related to reduction of antibiotic delivery due to a decreased gastric blood flow, a decrease in intragastric $\mathrm{pH}$ in cases 
of smoking, and nicotine could potentiate the vacuolating toxin activity of $\mathrm{H}$. pylori in gastric cells $[\mathbf{2 0 , 2 1}$. Seventy five patients were treated by bismuth containing quadruple therapy as ${ }^{1 \text { st }}$ line treatment for $\mathrm{H}$. pylori had higher eradication rate $(96 \%)$ in agreement with data from recent study in Kuwait [18] Alboraie et al., 2015 and fourth chinese national consensus report [22]. Also high eradication rate in consistent with previous two large studies [23,24].

The present study shows that 10 days bismuth quadruple therapy wasmore effective treatment with statistically significant higher eradication rate than 14 days clarithromycin standard triple therapy ( $96 \%$ vs. $77 \%$ ) in agreement with data from recent study in Kuwait [18] and consistent with previous international studies [25-27]. Furthermore, optimal therapeutic regimen for $\mathrm{H}$. pylori as it has high eradication rates exceeding $90 \%$ consistent with previous studies [13,14]. A total of 136 patients failed to cured from $\mathrm{H}$. pylori infection with 1 st line regimens, 98 patients ( $72 \%$ ) of them were treated by standard clarithromycin based therapy, 3 patients (2\%) were treated by Quadruple therapy while the remaining 35 patients were previously treated by other regimens (sequential, OAL). All those patients treated by 2 nd line regimens, 78 patients treated by Bismuth containing quadruple therapy (Pylera) and showed high eradication rate $97.4 \%$ in addition to 58 patients treated by Levofloxacin based triple therapy also showed high eradication rate $98.3 \%$. Levofloxacin-containing triple therapy and bismuth-containing quadruple therapy were effective as a second-line therapy for $\mathrm{H}$. pylori eradication consistent with previous study [28] moreover both regimens showed similar efficacy ( $>90 \%$ cure rate) the same as reported by previous study [29]. However with increased prevalence of primary levofloxacin resistance that has been recently reported and this may affect the efficacy of levofloxacin-based regimens [30]. Therefore, bismuth-containing quadruple therapy continues to represent avalid second-line treatment for H. pylori eradication, particularly in areas with high fluoroquinolones resistance.

\section{Limitation and Recommendation:}

Helicobacter pylori culture and sensitivity was not routinely performed and we could not identify susceptible H. pylori strains to clarithromycin and amoxicillin-containing regimens and data regarding antibiotic resistance among $\mathrm{H}$. pylori strains from Kuwait remain scarce so organized efforts are needed to document local and national patterns of resistance in order to guide the appropriate selection of $\mathrm{H}$. pylori therapy.

\section{References}

1- McCOLL K.E.: Clinical practice. Helicobacter pylori infection. New Engl. J. Med., 362: 1597-604, 2010.

2- GRAHAM D.Y., LU H. and YAMAOKA Y.: A report card to grade Helicobacter pylori therapy. Helicobacter, 12: 275-8, 2007.

3- SUGANO K., TACK J., KUIPERS E.J., et al.: Kyoto global consensus report on Helicobacter pylori gastritis. Gut., 64: 1353-67, 2015.

4- M. SELGRAD, J. BORNSCHEIN and P. MALFERTHEINER: "Guidelines for treatment of Helicobacter pylori in the East and West," Expert Review of AntiInfective Therapy, Vol. 9, No. 8, pp. 581-8, 2011.

5- LEE J.Y., KIM N., KIM M.S., et al.: Factors affecting first-line triple therapy of Helicobacter pylori including CYP2C19 genotype and antibiotic resistance. Dig. Dis. Sci., 59: 1235-43, 2014.

6- MALFERTHEINER P., MEGRAUD F., O'MORAIN C.A., et al.: Management of Helicobacter pylori infection-the Maastricht V/Florence Consensus Report, Gut., 66: 6-30, 2017.

7- VENERITO M., KRIEGER T., ECKER T., et al.: Metaanalysis of bismuth quadruple therapy versus clarithromycin triple therapy for empiric primary treatment of Helicobacter pylori infection. Digestion, 88: 33-45, 2013.

8- MALFERTHEINER P., BAZZOLI F., DELCHIER J.C., et al.: Helicobacter pylori eradication with a capsule containing bismuth subcitrate potassium, metronidazole, and tetracycline given with omeprazole versus clarithromycin-based triple therapy: A randomised, open-label, non-inferiority, Phase 3 trial. Lancet, 377: 905-13, 2012.

9- KIM S.G., JUNG H.K., LEE H.L., et al.: Guidelines for the diagnosis and treatment of Helicobacter pylori infection in Korea, 2013 revised edition. J. Gastroenterol. Hepatol., 29: 1371-86, 2014.

10- MALFERTHEINER P., MEGRAUD F., O'MORAIN C., et al.: Current concepts in the management of Helicobacter pylori infection: The Maastricht III Consensus Report. Gut., 56: 772-81, 2007.

11- CHUAH S.K., TSAY F.W., HSU P.I., et al.: A new look at anti-Helicobacter pylori therapy. World J. Gastroenterol., 17: 3971-5, 2011.

12- SELGRAD M. and MALFERTHEINER P.: Treatment of Helicobacter pylori. Curr. Opin. Gastroenterol., 27: 56570, 2011.

13- RIMBARA E., FISCHBACH L.A. and GRAHAM D.Y.: Optimal therapy for Helicobacter pylori infections. Nat. Rev. Gastroenterol. Hepatol., 8: 79-88, 2011.

14- LI B.Z., THREAPLETON D.E., WANG J.Y., et al.: Comparative effectiveness and tolerance of treatments for Helicobacter pylori: Systematic review and network meta-analysis. B.M.J., 351: h4052, 2015.

15- GRAHAM D.Y. and FISCHBACH L.: Helicobacter pylori treatment in the era of increasing antibiotic resistance. Gut., 59: 1143-53, 2010.

16- GISBERT J.P., PAJARES R. and PAJARES J.M.: Evolution of Helicobacter pylori therapy from a meta-analytical perspective. Helicobacter, 12 Suppl 2: 50-8, 2007. 
17-ALAZMI W.M., BUHAIMED W. and AL-MEKHAIZEEM K.: Efficacy of standard triple therapy in the treatment of Helicobacter pylori infection: Experience from Kuwait, Dig. Dis. Sci., Nov., 55 (11): 3120-3, 2010.

18- ALBORAIE M., SAAD M., AL-ALI J., et al.: Quadruple therapy versus standard triple therapy for eradication of h.pylori in Kuwait. Arab J. Gastroenterol., Sep.-Dec., 1693-4: 131-5, 2015.

19- ABDULLAHI M., ANNIBALE B., CAPOCCIA D., et al.: The eradication of Helicobacter pylori is affected by Body Mass Index (BMI). Obes. Surg., 18: 1450e4, 2008.

20- SUZUKI T., MATSUO K., ITO H., et al.: Smoking increases the treatment failure for Helicobacter pylori eradication. Am. J. Med., 119: 217e24, 2006.

21- ITSKOVIZ D., BOLTIN D., LEIBOVITZH H., et al.: Smoking increases the likelihood of Helicobacter pylori treatment failure. Dig. Liver Dis., Mar. 27. pii: S15908658 (17) 30790-9, 2017.

22- LIANG X., XU X., ZHENG Q., et al.: Efficacy of bismuthcontaining quadruple therapies for clarithromycin-, metronidazole-, and fluoroquinolone-resistant Helicobacter pylori infections in a prospective study. Clin. Gastroenterol. Hepatol., 11: 802-7, 2013.

23- O'MORAIN C., BORODY T., FARLEY A., et al.: Efficacy and safety of single-triple capsules of bismuth biskalcitrate, metronidazole and tetracycline, given with omeprazole, for the eradication of Helicobacter pylori: An international multicentre study. Aliment. Pharmacol. Ther., 17: 41520, 2003.

24- LAINE L., HUNT R., EL-ZIMAITY H., et al.: Bismuthbased quadruple therapy using a single capsule of bismuth biskalcitrate, metronidazole, and tetracycline given with omeprazole versus omeprazole, amoxicillin, and clarithro- mycin for eradication of Helicobacter pylori in duodena ulcer patients: A prospective, randomized, multicenter, North American trial. Am. J. Gastroenterol., 98: 562-7, 2003.

25- VENERITO M., KRIEGER T., ECKER T., et al.: Metaanalysis of bismuth quadruple therapy versus clarithromycin triple therapy for empiric primary treatment of Helicobacter pylori infection. Digestion, 88: 33-45, 2013.

26- MALFERTHEINER P., BAZZOLI F., DELCHIER J.C., et al.: Helicobacter pylori eradication with a capsule containing bismuth subcitrate potassium, metronidazole, and tetracycline given with omeprazole versus clarithromycin-based triple therapy: A randomised, open-label, non-inferiority, phase 3 trial. Lancet, 377: 905-13, 2011.

27- LAINE L., HUNT R., EL-ZIMAITY H., et al.: Bismuthbased quadruple therapy using a single capsule of bismuth biskalcitrate, metronidazole, and tetracycline given with omeprazole versus omeprazole, amoxicillin, and clarithromycin for eradication of Helicobacter pylori in duodenal ulcer patients: A prospective, randomized, multicenter, North American trial. Am. J. Gastroenterol., 98: 562-7, 2003.

28- MARIN A.C., McNICHOLL A.G. and GISBERT J.P.: A review of rescue regimens after clarithromycin-containing triple therapy failure (for Helicobacter pylori eradication). Expert Opin. Pharmacother., 14: 843-61, 2013.

29- Di CARO S., FINI L., DAOUD Y., et al.: Levofloxacin/ amoxicillin-based schemes vs quadruple therapy for Helicobacter pylori eradication in second-line. World J. Gastroenterol., 18: 5669-78, 2012.

30- SARACINO I.M., ZULLO A., HOLTON J., et al.: High prevalence of primary antibiotic resistance in Helicobacter pylori isolates in Italy. J. Gastrointestin. Liver Dis., 21: 363-5, 2012.

\section{دراسة عن فعالية نظم العلاج المختلفة على القضاء

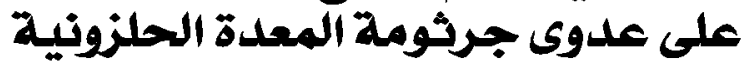

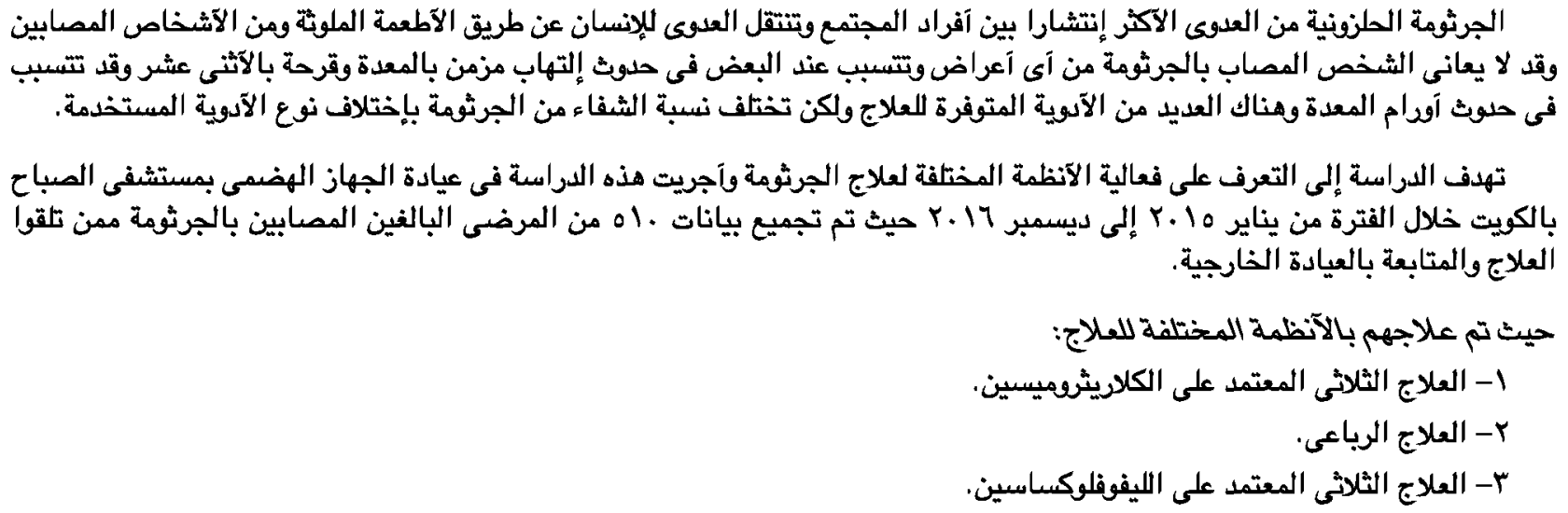

